\title{
Assessment of Current Status of Fluorosis in North-Western Districts of Tamil Nadu Using Community Index for Dental Fluorosis
}

\author{
R. Hari Kumar, A. L. Khandare, G.N.V. Brahmam, K.Venkiah, Ch. Gal Reddy and \\ B. Sivakumar \\ National Institute of Nutrition (ICMR), Jamai Osmania P.O., Hyderabad 500 007, \\ Andhra Pradesh, India
}

KEYWORDS Dental Mottling. Community Index for Dental Fluorosis

\begin{abstract}
India is one of the countries where hydrofluorosis is a major public health problem, affecting 18 of the 33 constituent States of the Country. Tamil Nadu is one of the Southern states having 10 of the 29 districts affected with fluorosis. Fluorosis is caused by ingestion of excess fluoride mainly through drinking water contamination. A cross sectional study was undertaken in 13 selected villages of five contiguous North western districts of Tamil Nadu viz: Vellore, Dharmapuri, Krishnagiri, Salem and Erode to assess the prevalence of fluorosis, adopting stratified random sampling procedure. A total of 8700 individuals, including 1745 children in the age group of 5-14 years were examined from 2800 Households for dental mottling. The study revealed that community bore wells formed the major source of drinking water among the villages. One hundred and twenty six drinking water samples were collected and the mean fluoride content was found to be more than WHO cut off level of $1.5 \mathrm{ppm}$ in seven of the 13 villages surveyed. The prevalence of dental mottling (DM) was high among the total population in the districts of Dharmapuri (36\%), Krishnagiri (24\%) and Salem (33\%), where the mean fluoride levels were 2.7, 2.2, and 1.2ppm respectively, however, the prevalence of skeletal deformities was low. The prevalence of DM was still high among the children (5-14 years) in the above three districts $(53 \%, 43 \%$ and $42 \%$ respectively). Evaluation by Community Index for Dental fluorosis (CIDF) (>42\% is considered as public health) suggested that the fluorosis is of public health importance in most of the villages. Such high prevalence of fluorosis requires community based interventions through supply of fluoride free surface water from a river, which is the most effective long-term strategy to control and prevent fluorosis.
\end{abstract}

\section{INTRODUCTION}

Hydrofluorosis is a major public health problem in India, affecting 62 million people, including 6 million children in 18 of the 33 constituent States and Union territories of the country, due to consumption of excess fluoride through drinking water. (Susheela, 1999).

The spectrum of manifestations of fluorosis include dental mottling, skeletal deformities such as Genu varum, Genu valgum, bowing of tibia, Kyphosis, exostosis, bone/muscular tenderness, wasting, restricted joint movements, pain in abdomen, diarrhoea, constipation, blood in stools etc.

Though, drinking water is the main source of fluoride, beverages like tea also contributes to a significant amount of fluoride intake. The cause of fluorosis can be attributed to decrease in rainfall and uncontrolled exploitation of ground water, leading to increased concentration of different minerals in the subsoil structure

Address for correspondence: R.Hari Kumar, National Institute of Nutrition. Jamai Osmania, Hyderabad 500 007, Andhra Pradesh, India

Phone: 91-040-27008921 Ext. No. 255.

E-mail: drharikumar1959@yahoo.co.in including fluoride. (Michel, 1972). In addition, construction of large water reservoirs is also known to bring about changes in the ground water level. (Krishnamachari and Sivakumar, 1976).

Assessment of prevalence of dental mottling in the community is the most convenient biomarker of chronic exposure to excess fluoride. Dental mottling generally occurs in permanent teeth and visible clearly in all age groups of 5 years and above, therefore the prevalence among the children of growing age i.e., from 5-14 years is high is considered as the reflection of the current problem of the fluorosis. On the basis of prevalence of dental mottling (5-20\%) among the children of school going age of 5-14 years, earlier studies (Krishnamachari and Sivakumar, 1976; Karthikeyan and Shunmugasunderraj, 2000) indicated that 10 out of 29 districts of Tamil Nadu (Susheela, 1999). are endemic for fluorosis and also the data generated by Tamil Nadu Water supply and Drainage (TWAD) Board indicated that more than $50 \%$ of the ground water sources have fluoride levels of more than $1.0 \mathrm{ppm}$ in the districts of Vellore, Krishnagiri, Dharmapuri and Salem. The present study was therefore carried out to assess the severity of the problem on the 
basis of an index "Community Index of Dental fluorosis" (CIDF) for making comparisons between the districts and prioritizing them for recommending appropriate public health measures.

\section{METHODOLOGY}

Stratified random sampling procedure was adopted for selection of water sources and villages. The data generated by TWAD board during 1999-2000, on fluoride levels in drinking water, formed basis for selection of water sources and villages. The fluoride levels in drinking water in the five selected districts according to TWAD board ranged between 0.5-6.0ppm. For the purpose of study, the water sources in each of the districts were stratified into three categories based on the fluoride levels in drinking water as < 2, 2-4, and 4-6 ppm. From each of these categories, one water source was selected randomly, and the corresponding village was identified from each district for the study. A total of 9 villages from three districts, at the rate of one village from each of category $(<2,2-4$, and 4-6 ppm) of fluoride level were covered from the districts of Dharmapuri, Krishnagiri and Salem, while in the districts of Vellore and Erode, only two villages per district were covered because none of the water sources had fluoride levels of 4-6 ppm. In each of the selected villages, about 1000 population, residing in about nearly 250 households around the selected water source were covered for clinical examination.

All the available members of the selected household were subjected to clinical examination for dental mottling and skeletal fluorosis. In addition, information on family size and source of drinking water was collected. Water samples from all the available water sources along with the selected source were collected, for estimation of fluoride levels.

Clinical examination for dental mottling was carried out in daylight using "Smith's" classification.

Normal: Ivory white enameled teeth,

Grade 1: White opaque patches,

Grade 2: Dark Yellow to brownish discoloration. Grade 3: Discoloration with pitting of teeth (chipping of enamel).

A new index "Community Index of Dental Fluorosis" (CIDF) designed by Das (Das, !997), based on smith's classification (Murray, 1986) was used to compare the severity of disease between selected districts. The calculation of CIDF involved allotting of scores from 0, 1, 2 and 3 to each of the normal and grade I, II and grade III of dental mottling respectively among children of 5-14 years children. The CIDF is obtained by dividing the total score obtained for all the children examined by the total number of children examined and expressed as percent, using the following formula.

Formula: CIDF=Total score X 100 / Number of children examined.

Estimation of fluoride content in the water samples was done in the field by ion selective electrode method, by using Orion ion specific electrode (EA940, Boston MA).

The advantage of the CIDF over other indices such as "Fluorosis community Index" (FCI) and the "Dental fluorosis Index" (DFI), is that it considers only the age group of 5-14 years, where the prevalence of dental mottling is at peak, while the other indices considers all age groups and dilute the results. In addition this method is simpler for calculation and can be easily interpretable. 11.5 .

The data was analyzed using SPSS version

\section{RESULTS}

A total of 8700 individuals, including 1745 children of 5-14 years of age from $2800 \mathrm{HHs}$ were examined for dental mottling from 13 villages of five districts namely Vellore, Dharmapuri, Krishnagiri and Salem and Erode. The proportion of 5-14 years children to total population (20\%) covered in the current survey was observed to be similar to that of Census of India-2001 (19\%) thus ruling out the possibility of non coverage and its affect on the interpretation of results. One hundred and twenty six water samples from different drinking water sources were collected from these 13 villages and fluoride levels were analyzed.

The study indicated that, the community bore wells fitted with electric pump formed the major source of drinking water. In two villages of Salem district and one village in Erode district, in addition to the bore water, drinking water from Cauvery River was also being supplied after treatment (filtration and chlorination). A majority of the bore wells were 200-300 feet in depth and occasionally touching 700 feet. 
Table 1: Distribution (\%) population by source of water, mean fluoride levels and prevalence of dental mottling

\begin{tabular}{|c|c|c|c|c|c|}
\hline \multirow[t]{2}{*}{ District } & \multirow[t]{2}{*}{ Panchayat } & \multirow{2}{*}{$\begin{array}{c}\% \text { Population using } \\
\text { bore wells }\end{array}$} & \multirow{2}{*}{$\begin{array}{c}\text { Mean } \\
\text { fluoride level } \\
\text { (ppm) }\end{array}$} & \multicolumn{2}{|c|}{$\%$ Prevalence of Dental mottling } \\
\hline & & & & All age groups) & 5-14 years \\
\hline \multirow{2}{*}{ Vellore } & Dana Konda Palli & 100 & 2.1 & 17.4 & 34.2 \\
\hline & Madanancheri & 100 & 1.1 & 16.1 & 33.3 \\
\hline \multirow[t]{3}{*}{ Dharmapuri } & Chinna Kuppam & 100 & 1.8 & 27.3 & 43.3 \\
\hline & Pappireddi Patti TP & 100 & 1.7 & 40.8 & 54.2 \\
\hline & Pattukoanam Patti & 100 & 4.6 & 38.5 & 48.5 \\
\hline \multirow{3}{*}{ Krishnagiri } & Alapatti & 100 & 1.9 & 20.4 & 16.4 \\
\hline & Periamuthur & 100 & 2.9 & 34.3 & 60.6 \\
\hline & Khammam Palli & 100 & 1.7 & 14.8 & 25.5 \\
\hline \multirow[t]{3}{*}{ Salem } & Virudhasam Patti & 50 & 1.2 & 34.0 & 50.8 \\
\hline & Ramreddi Patti & 85.7 & 1.1 & 33.7 & 36.3 \\
\hline & Chittur & 100 & 1.3 & 29.4 & 41.1 \\
\hline \multirow[t]{2}{*}{ Erode } & Villarasam Patti & 64.7 & 1.1 & 24.3 & 30.0 \\
\hline & Cinniam Palayam & 100 & 0.6 & 13.4 & 14.3 \\
\hline
\end{tabular}

Fluoride Levels in Drinking Water: The fluoride content of the drinking water from various sources in the areas covered ranged from $0.47 \mathrm{ppm}$ to $6.6 \mathrm{ppm}$. The mean fluoride levels of drinking water in these villages ranged from a low of 0.6 to a high of $4.6 \mathrm{ppm}$ (Table 1). In seven out of the 13 villages, the mean fluoride of the drinking water sources was more than the WHO cut off level of $1.5 \mathrm{ppm}$ (WHO, 1984).

Clinical Signs: Dental mottling of different grades (Grade 1-3) was found to be prevalent in all the 13 villages of all the five selected districts. (Table 1). The prevalence of overall dental mottling among the total population ranged from a low of $17 \%$ in Vellore district to a high of $36 \%$ in Dharmapuri district.

The prevalence of dental mottling according to age groups indicated that the prevalence of dental mottling was highest among the children of 5-14 years age group, in all the districts, while it was negligible among the children of below 4 years (Fig. 1). The peak of prevalence of dental mottling in this age group of children was also visible when data of all the districts is pooled together (Table 2). Among the five districts, the prevalence of dental mottling in the age group of 5-14 years was more than $40 \%$ in the districts of Salem, Dharmapuri and Krishnagiri districts.

According to the Smith's classification, the prevalence of severe grade dental grade mottling (Grade III) was relatively higher in the districts of Salem and Dharmapuri (3\%), followed by Krishnagiri, Vellore and Erode (1.9, 1.5, 0.4\%).

The CIDF was more than $42 \%$ for all the villages surveyed except for "Villarasam patti and Cinniam palayam of Erode district. At district level, CIDF was more than $42 \%$ in Vellore, Dharmapuri, Krishnasgiri, and Salem (55-81\%), while that of Erode was about $30 \%$ (Table 3). The prevalence of severe skeletal deformities like genuvalgum and genuvarum was less than $1 \%$.

\section{DISCUSSION}

Fluorosis was first described by Shortt and co-workers (Shortt et al., 1937; Daver, 1945, Siddiqui et al.,1961) as a public health problem in different parts of India. Presently, it is a major health problem in 18 States with 65 million people at risk and 6 million children are seriously affected (Susheela,1999). The crippling bone deformities (genu valgum, genu varum, anteroposterior bowing of tibia) have been associated with high fluoride in drinking water. (Krishnamachari, and Krishnaswamy, 1973; Moudgil et al.,1986; Srivastava et al., 1989; Chakma et al., 2000).

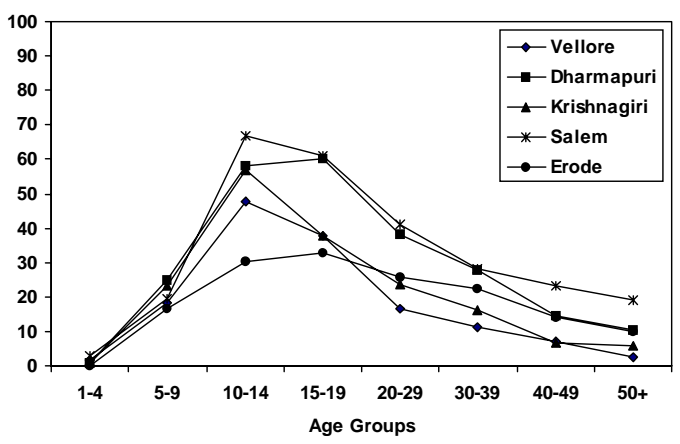

Fig. 1. District wise prevalence $(\%)$ of dental mottling among various age groups $(\%)$ 
Table 2: Distribution (\%) of prevalence of dental mottling by age groups

\begin{tabular}{|c|c|c|c|c|c|c|c|c|c|c|c|c|}
\hline \multirow{2}{*}{$\begin{array}{l}\text { Age group } \\
\text { (in yrs.) }\end{array}$} & \multicolumn{2}{|c|}{ Vellore } & \multicolumn{2}{|c|}{ Dharmapuri } & \multicolumn{2}{|c|}{ Krishnagiri } & \multicolumn{2}{|c|}{ Salem } & \multicolumn{2}{|c|}{ Erode } & \multicolumn{2}{|c|}{ Pooled } \\
\hline & $n$ & $(\%)$ & $n$ & $(\%)$ & $n$ & $(\%)$ & $n$ & $(\%)$ & $n$ & $(\%)$ & $n$ & $(\%)$ \\
\hline $1-4$ & 130 & 1.5 & 114 & 0.9 & 143 & 0.7 & 113 & 2.7 & 46 & 0.0 & 546 & 1.3 \\
\hline $5-14$ & 308 & 33.8 & 725 & 53.3 & 478 & 45.2 & 450 & 41.8 & 210 & 24.8 & 2171 & 18.1 \\
\hline $15-19$ & 106 & 37.7 & 287 & 60.3 & 235 & 37.9 & 177 & 61.0 & 64 & 32.8 & 869 & 10.0 \\
\hline$\geq$ & 786 & 9.6 & 1239 & 24.4 & 1087 & 14.0 & 1321 & 28.1 & 705 & 18.0 & 5138 & 16.0 \\
\hline Pooled & 1330 & 13.4 & 2365 & 18.3 & 1943 & 14.3 & 2061 & 14.1 & 1025 & 15.3 & 8724 & 15.3 \\
\hline
\end{tabular}

Table 3: Community Index of dental fluorosis

\begin{tabular}{|c|c|c|c|c|c|c|c|c|c|c|c|c|c|}
\hline \multirow[t]{2}{*}{ Village } & \multirow{2}{*}{$N$} & \multirow{2}{*}{$\begin{array}{c}\text { Normal. } \\
\text { Score }=0 \\
n\end{array}$} & \multicolumn{3}{|c|}{$\begin{array}{l}\text { Grade I. } \\
\text { Score = I }\end{array}$} & \multicolumn{3}{|c|}{$\begin{array}{l}\text { Grade II. } \\
\text { Score }=2\end{array}$} & \multicolumn{3}{|c|}{$\begin{array}{l}\text { Grade III. } \\
\text { Score }=3\end{array}$} & \multirow[t]{2}{*}{$\begin{array}{c}\text { Total } \\
\text { weights }\end{array}$} & \multirow[t]{2}{*}{$\begin{array}{l}\text { Total } \\
\text { CIDF }\end{array}$} \\
\hline & & & $n$ & Weights & $C I D F$ & $N$ & Weights & $C I D F$ & $n$ & Weights & $C D I F$ & & \\
\hline Dana Konda Palli & 146 & 98 & 19 & 19 & 12.8 & 19 & 38 & 26.0 & 12 & 36 & 24.6 & 93 & 63.6 \\
\hline Madanancheri & 162 & 108 & 31 & 31 & 19.1 & 21 & 42 & 25.9 & 2 & 6 & 3.7 & 79 & 48.5 \\
\hline Vellore & 308 & 204 & 50 & 50 & 16.2 & 40 & 80 & 26.0 & 14 & 42 & 13.6 & 172 & 55.8 \\
\hline Chinna Kuppam & 154 & 77 & 54 & 54 & 35.1 & 21 & 42 & 27.3 & 2 & 6 & 3.9 & 102 & 66.3 \\
\hline Papireddi Patti & 461 & 211 & 137 & 137 & 29.7 & 86 & 172 & 37.3 & 27 & 81 & 17.5 & 390 & 84.5 \\
\hline Pattukonam patti & 110 & 51 & 30 & 30 & 27.3 & 22 & 44 & 40 & 7 & 21 & 19.1 & 95 & 86.4 \\
\hline Dharmapuri & 725 & 339 & 221 & 221 & 30.5 & 129 & 258 & 35.6 & 36 & 108 & 14.8 & 587 & 80.9 \\
\hline Alapatti & 251 & 149 & 48 & 48 & 19.1 & 41 & 82 & 32.6 & 13 & 39 & 15.3 & 169 & 67.3 \\
\hline Periamuthur & 155 & 61 & 47 & 47 & 30.3 & 41 & 82 & 52.9 & 6 & 18 & 11.6 & 147 & 94.8 \\
\hline Khammam Palli & 72 & 52 & 9 & 9 & 12.5 & 11 & 22 & 30.6 & 0 & 0 & 0 & 31 & 43.1 \\
\hline Krishnagiri & 478 & 262 & 104 & 104 & 21.8 & 93 & 186 & 38.9 & 19 & 57 & 11.9 & 347 & 72.6 \\
\hline Virudasam Patti & 125 & 62 & 31 & 31 & 24.8 & 25 & 50 & 40.0 & 7 & 21 & 16.8 & 102 & 81.6 \\
\hline Ramireddi Patti & 179 & 114 & 47 & 47 & 26.3 & 12 & 24 & 13.4 & 6 & 18 & 10.1 & 89 & 49.8 \\
\hline Chittur & 146 & 86 & 48 & 48 & 32.8 & 5 & 10 & 6.9 & 7 & 21 & 14.3 & 79 & 54.1 \\
\hline Salem & 450 & 262 & 126 & 126 & 28.0 & 42 & 84 & 18.6 & 20 & 60 & 13.3 & 270 & 59.9 \\
\hline Villarasam Patti & 110 & 77 & 26 & 26 & 23.6 & 6 & 12 & 10.9 & 1 & 3 & 2.7 & 41 & 37.2 \\
\hline Cinniam Palayam & 100 & 81 & 17 & 17 & 17.0 & 2 & 4 & 4.0 & 0 & 0 & 0 & 21 & 21.0 \\
\hline Erode & 210 & 158 & 43 & 43 & 20.4 & 8 & 16 & 7.6 & 1 & 3 & 1.4 & 62 & 29.5 \\
\hline All districts & 2171 & 1225 & 544 & 544 & 25.1 & 312 & 624 & 28.7 & 90 & 270 & 12.41 & 1438 & 66.2 \\
\hline
\end{tabular}

Earlier studies by the National Institute of Nutrition in the district of Coimbatore (Krishnamachari, and Sivakumar 1976) and the recent studies in the districts of Salem (Rajan, 1989) and Dharmapuri (Karthikeyan and Shunmugasunderraj, 2000), in the State Tamil $\mathrm{Nadu}$, implicate high levels of fluoride in drinking water to high prevalence of dental mottling. The data supplemented by the TWAD board also indicated that, 3,555 habitations spread over 10 districts have drinking water sources with fluoride content more than the permissible limits $(1.5 \mathrm{ppm})$ and a majority of these habitations belonged to the districts of Vellore, Dharmapuri, Krishnagiri, Salem and Erode, therefore these districts could be considered to be more seriously affected.

These districts are located on the NorthWestern part of the Tamil Nadu State with the Cauvery river flowing between the Dharmapuri and Salem on one side and Erode on the other side. A reservoir named "Mettur dam" was constructed in the district of salem for the purpose of irrigation in Salem and Erode districts.

The present study revealed that the population of the study area mostly depended on ground water, drawn from community bore wells with fluoride levels ranging from 0.4-6 ppm. While, WHO (1984) has suggested a cut off level of $1.5 \mathrm{ppm}$ of fluoride, it is hold by some experts that a lower level of $1.0 \mathrm{ppm}$ as safe limit in tropical climates like in India, where higher amounts of drinking water is consumed. It was observed that, the proportion of water sources having $1.0 \mathrm{ppm}$ of fluoride was highest in the villages of Dharmapuri and Krishnagiri (100\%), followed by Vellore and Salem (70-80\%) and Erode (17\%). The categorization of data collected by the TWAD board also supports the present study, where $>50 \%$ of the water sources had 1.0 ppm of fluoride in the districts of Krishnagiri (62\%) followed by Vellore (60\%), Salem (56\%), Dharmapuri (53\%), and Erode (26\%). In addition, with $1.5 \mathrm{ppm}$ as suggested by WHO also followed 
a similar pattern, with a maximum proportion of water sources $(42 \%)$ in Krishnagiri district followed by Dharmapuri (35\%), Salem (27\%), Vellore (12\%) and Erode (8\%). The mean fluoride levels calculated at village level also showed that, all the villages except for Cinniam Palayam village of Erode district had unacceptable levels of fluoride. Therefore, it can be deduced that the proportion of population exposed to higher levels of fluoride is greater in the four districts of Vellore, Krishnagiri, Dharmapuri and Salem than the Erode district, which may be due to geophysical locations.

The prevalence of Grade III dental mottling, which ranged from $0.4 \%$ in Erode to $3.2 \%$ in Dharmapuri district indicated the severity of the fluorosis.

Skeletal deformities which would need much longer duration of exposure to excess fluoride levels in drinking water, appeared not to be of major public health problem, as the prevalence was less than $1 \%$. However, dental mottling could be considered as the alarming signal of impending skeletal deformities with continued exposure to fluoride.

The prevalence of dental fluorosis expressed both on total population and on children of 5-14 years, though, high in the districts with high mean fluoride levels, no strong association was noted between the fluoride content and prevalence of dental fluorosis. This may be due to heterogeneous nature of the population, in terms of differences in socio-economic status and dietary habits like consumption of "Ragi" millet (rich in calcium) by the population in the district of Krishnagiri. Variations in intake of foods like Jowar, Ragi and milk are known to alter the clinical manifestations of fluorosis.

The CIDF is interpreted as, a value above $42 \%$ indicating the problem as significant public health importance, that may need immediate community based intervention such as establishment of defluoridation plants or supply of fluoride free drinking water. The index value between $28-42 \%$ indicates borderline areas of endemicity, which may need health education as an intervention, including training in the household defluoridation techniques. Index value $<28 \%$ indicate existence of diseases but of not public health importance. Therefore, the CIDF of more than $42 \%$ in all the villages surveyed in four districts indicate immediate necessity of community-based interventions like community- based defluoridation of drinking water or supply of fluoride free surface water.

\section{CONCLUSION}

Endemic fluorosis is of public health problem in most of the villages studied, as the dental mottling among the children of 5-14 years was more than $20 \%$. The CIDF was also more than $42 \%$ indicating community based long-term intervention strategy of supply of safe drinking water.

\section{ACKNOWLEDGEMENTS}

We express our sincere thanks to Prof. N. K. Ganguly, Director General, Indian Council of Medical Research for providing us an opportunity to conduct this study. Our thanks are due to Dr. M. D. Gupte, Director, of National Institute of Epidemiology and for the guidance throughout the study.

We are also thankful to G. Shanker Rao, Technical Assistant, Mr. Ch. Krishna, Technician, Mr. C. Saibabu, Mr. S. P. V. Prasad, Lab Assistants from NIN for their technical help in preparation of final report.. We are extremely grateful to the community for their co-operation, without which the survey would not have been possible.

\section{REFERENCES}

Chakma, T.P., Rao, Vinay, Singh, S.B. and Tiwary, R.S.: Endemic genu valgum and other bone deformities in two villages of Mandla district in central India. Fluoride, 33: 187-195 (2000).

Das, P.K.: Computation of a community index of dental fluorosis. Indian Journal of Public Health, XXXXI(3): 86-89 (1997).

Daver, M.B.: Occurrence of Fluorosis in Endemic Forms in Hyderabad State. Indian Med.Gaz. 80: 332 (1945).

Karthikeyan,G. and Shunmugasunderraj, A.: Isopleth Mapping and in situ fluoride dependence on water quality in the Krishnagiri Block of Tamil Nadu In South India. Fluoride, 33(3): 121-127 (2000).

Krishnamachari, K.A.V.R. and Sivakumar, B.: Endemic genu valgum a new dimension to the fluorosis problem in India. Fluoride, 9: 185-200 (1976).

Krishnamachari, K.A.V.R. and Krishnaswamy, Kamala: Genu valgum and osteoporosis in area of endemic fluorosis. Lancet, ii: 877-879 (1973).

Michel, A. A.: The impact of modern irrigation technology in the Indus and Helmand Basins of SouthWest Asia. In: The Careless Technology. M.T. Parvar and J.P. Milton (Eds.) (1972). Cited from Michael A.A: Fluoride, 9(4): 257 (1976).

Moudgil, A., Srivastava, R. N., Vasudev, A., Bagga, A. and 
Gupta, A.: Fluorosis with crippling skeletal deformities. Ind. Pediatrics, 23: 769-773 (1986). Murray, J.J.: Appropriate Use of Fluoride for Human Health. World Health Organization, Geneva (1986).

Rajan, B.P.: Incidence of Dental Fluorosis vs.Dental Caries in Salem District of Tamil Nadu in South India. Report. Ministry of Environment and Forests, Government of India, New Delhi (1989).

Shortt, H. E., Pandit, C. G. and Raghavachari, T.N.S.: Endemic Fluorosis in the Nellore District of South India. Indian Med. Gaz., 72: 396 (1937).

Siddiqui, A. H.: Fluorosis in Nalgonda District, Hyderabad,
Deccan., Br. Med. J., 2: 1408 (1955).

Singh, A. and Jolly, S.S: Endemic Fluorosis.Q. J.Med., 30: 357 (1961).

Srivastava, R. N., Gill, D.S., Maudgil, A., Menon, R. K., Thomas, M. and Andona,.P. D.: Normal ionized calcium, parathyroid hyper secretion and elevated osteocalcin and family with fluorosis. Metabolism, 38: 120-124 (1989).

Susheela, A.K.: Fluorosis management program in India. Curr. Sci., 77: 1250-1255 (1999).

WHO: Guidelines for Drinking Water Quality. World Health Organization, Geneva (1984) 